\title{
AGROTÓXICOS: LEVANTAMENTO DOS MAIS UTILIZADOS NO OESTE PAULISTA E SEUS EFEITOS COMO DESREGULADORES ENDÓCRINOS
}

\author{
Tamiris Garbiatti de Oliveira ${ }^{1}$ \\ Ana Paula Alves Favareto ${ }^{2}$ \\ Patricia Alexandra Antunes ${ }^{3}$
}

RESUMO: A utilização desenfreada de agrotóxicos está contribuindo com o agravamento da poluição ambiental, pois na maioria das vezes a forma de aplicação desses produtos facilita a contaminação de solos e recursos hídricos, afetando espécies aquáticas e terrestres, podendo ainda interferir na saúde das pessoas que estão envolvidas diretamente e indiretamente com a aplicação. Considerando a grande área ocupada pela a monocultura de cana-de-açúcar na região do Oeste Paulista, este trabalho trata-se de um levantamento dos produtos sintéticos mais utilizados nesta região, provenientes principalmente dessa cultura, bem como a problemática envolvida pela utilização dos agrotóxicos, e estudos que demonstram as interferências causadas por estes em espécies vivas. Com isso mostra-se a importância de testes toxicológicos mais específicos para estes produtos.

Palavras-chave: Cosumo de agrotóxicos. Toxicidade. Problemas a saúde

${ }^{1}$ Química, UNOESTE, Mestranda do Mestrado em Meio Ambiente e Desenvolvimento Regional, UNOESTE, bolsista PROSUP/CAPES, tamigarbiatti @gmail.com.

${ }^{2}$ Doutora em Biologia Celular e Estrutural, Professora e Pesquisadora, UNOESTE, anafavareto@unoeste.br

${ }^{3}$ Doutora em Química Analítica, Professora e Pesquisadora, UNOESTE, antunes@unoeste.br 


\section{1- INTRODUÇÃO}

Atualmente existe uma problemática envolvendo a questão ambiental, que é afetada diretamente pelo processo de desenvolvimento do homem, e de maneira negativa. $O$ grande crescimento populacional, as exigências de consumo aumentaram, havendo uma necessidade de produção de alimentos muito intensa. Com isso, o ecossistema natural, passou a ser considerado um agroecossistema, onde ocorre a expansão das monocultoras, elimina-se a vegetação natural, reduzindo assim a diversidade do local, as plantas e animais. Sendo assim, as características de autoregulação dos ecossistemas naturais, que são proporcionados pela biodiversidade, são perdidas. Isso leva a consequências, pois menos elementos de controle natural atuam, e tendendo há uma dinâmica irregular entre os seres, que faz com que o homem tenha que interferir para o controle (ODUM, 1988).

Com isso o homem faz uso da tecnologia para melhorar a qualidade de vida e aumentar a produtividade, interferindo diretamente nos recursos naturais. Para atender a demanda agroindustrial, produtos são desenvolvidos com o intuito de aumentar ou melhorar a produtividade agrícola, diminuir ou eliminar as interferências causadas por insetos, plantas daninhas, etc. que dificultam o desenvolvimento da produção. Segundo Peres, Rozemberg, Lucca (2005, p. 1836) "não se pode negar que a tecnologia no campo proporciona o crescimento em termo de produtividade".

Porém existe uma situação ambivalente, por um lado, a incorporação tecnológica que possibilita o aumento e a diversificação da produção e por outro, o surgimento de novas injúrias à saúde e à segurança daqueles que utilizam tais tecnologias, dos organismos vivos presentes no ambiente e de toda a população. (PERES, ROZEMBERG, LUCCA 2005)

Uns dos principais produtos que se enquadra nesta questão são os agrotóxicos, pois eles são desenvolvidos com o intuito de alterar a composição da fauna e flora, eliminando assim efeitos possivelmente nocivos que seres vivos podem causar nas culturas. E com a elevada utilização têm ocorrido grandes impactos, pois esses produtos acabam sendo lixiviados, afetando as águas superficiais, os lençóis freáticos, além de 
afetar os organismos vivos de uma forma geral, podendo até acarretar danos na saúde do homem (BRASIL, 2002; CARSON, 2010). Esses produtos, no entanto podem chegar de diversas maneiras a influenciar a saúde humana, como através da exposição por meio de aplicações, pulverizações, na cadeia alimentar, consumo de frutas, verduras e água contaminada.

Muitos estudos têm mostrado que vários agrotóxicos podem afetar o sistema reprodutivo masculino de animais e também o desenvolvimento embrio-fetal, após exposição in utero. Dentre as alterações reprodutivas observadas após exposição durante o período gestacional, destacam-se restrição de crescimento intrauterino e malformações fetais. Já no sistema reprodutor masculino, alterações como diminuição de espermatozóides e aumento de espermatozóides danificados (apresentando dano do DNA) são exemplos que podem ocorrer em animais expostos a esses compostos. (BAIRD, 2002; DALLEGRAVE, E. et al. 2007; GHISELLI; JARDIM, 2007; SPIRO; STIGLIANI, 2008; AKCHA; SPAGNOL; ROUXEL, 2012;. FEYZI-DEHKHARAGNI et al. 2012). São muitas as evidências de que estes compostos podem causar alterações, mas até o momento não se sabe de que forma eles interagem com as células e e/ou DNA para causar os danos.

Dessa forma, estudos que avaliem as alterações causadas por produtos químicos, por meio de testes in vivo e in vitro, são de grande importância, pois fornecem informações que podem ser utilizadas como ferramentas para ajudar a compreender como essas substâncias interagem com organismos, entendendo de fato como podem gerar danos à saúde do meio ambiente e dos seres humanos. Estas informações podem subsidiar a implementação de políticas governamentais de saúde pública, que regularizem a utilização destes compostos químicos em níveis seguros para exposição humana (MORRISON et al.,1992; WEISENBURGER, 1993).

\section{2- CONTEXTUALIZAÇÃO DO USO REGIONAL DOS AGROTÓXICOS}


Um dos fatores que contribuem para o elevado crescimento e manutenção da agricultura é o desenvolvimento de produtos, como no caso os agrotóxicos. De acordo com o Decreto 4.074 (BRASIL, 2002), defini-se agrotóxico como:

\begin{abstract}
Agrotóxicos e afins - produtos e agentes de processos físicos, químicos ou biológicos, destinados ao uso nos setores de produção, no armazenamento e beneficiamento de produtos agrícolas, nas pastagens, na proteção de florestas, nativas ou plantadas, e de outros ecossistemas e de ambientes urbanos, hídricos e industriais, cuja finalidade seja alterar a composição da flora ou da fauna, a fim de preservá-las da ação danosa de seres vivos considerados nocivos, bem como as substâncias e produtos empregados como desfolhantes, dessecantes, estimuladores e inibidores de crescimento.
\end{abstract}

De acordo com a Agência Nacional de Vigilância Sanitária - ANVISA, em 2008 o Brasil alcançou o primeiro lugar no ranking de maior consumidor de agrotóxicos do mundo. Este mercado cresceu de 6,6 bilhões de dólares em 2009 para 7,3 bilhões em 2010, sendo que as culturas de soja, algodão, cana-de-açúcar e citros responderam por 82\% das vendas (SINDAG, 2011; ANVISA, 2012).

O estado de São Paulo se destacou em 2006 como o maior consumidor brasileiro de agrotóxicos, representando $20,6 \%$ do faturamento total de agrotóxicos negociados no Brasil (FERREIRA; VEGRO; CAMARGO, 2008). Sendo a classe de herbicidas a mais utilizada, sendo $43,1 \%$ do faturamento total do estado. As vendas estão destinadas principalmente ao cultivo de cana-de-açúcar, soja e milho, seguida pelas seguintes classes: inseticidas $(30,1 \%)$, fungicidas $(16,6 \%)$, acaricidas $(7,6 \%)$ entre outras (2,6\%) (FERREIRA; VEGRO; CAMARGO, 2008). Segundo o IBGE (2010), o percentual dos ingredientes ativos de agrotóxicos distribuídos por classe de uso no Brasil em 2005, destacaram-se o glifosato, 2,4-D ácido e Atrazina na classe dos herbicidas, na classe dos inseticidas, o metamidofós, endosulfan e parationa metílica, e na classe dos fungicidas, o mancozebe, o oxicloreto de cobre e cabendazim, como é mostrado na Figura 1. 


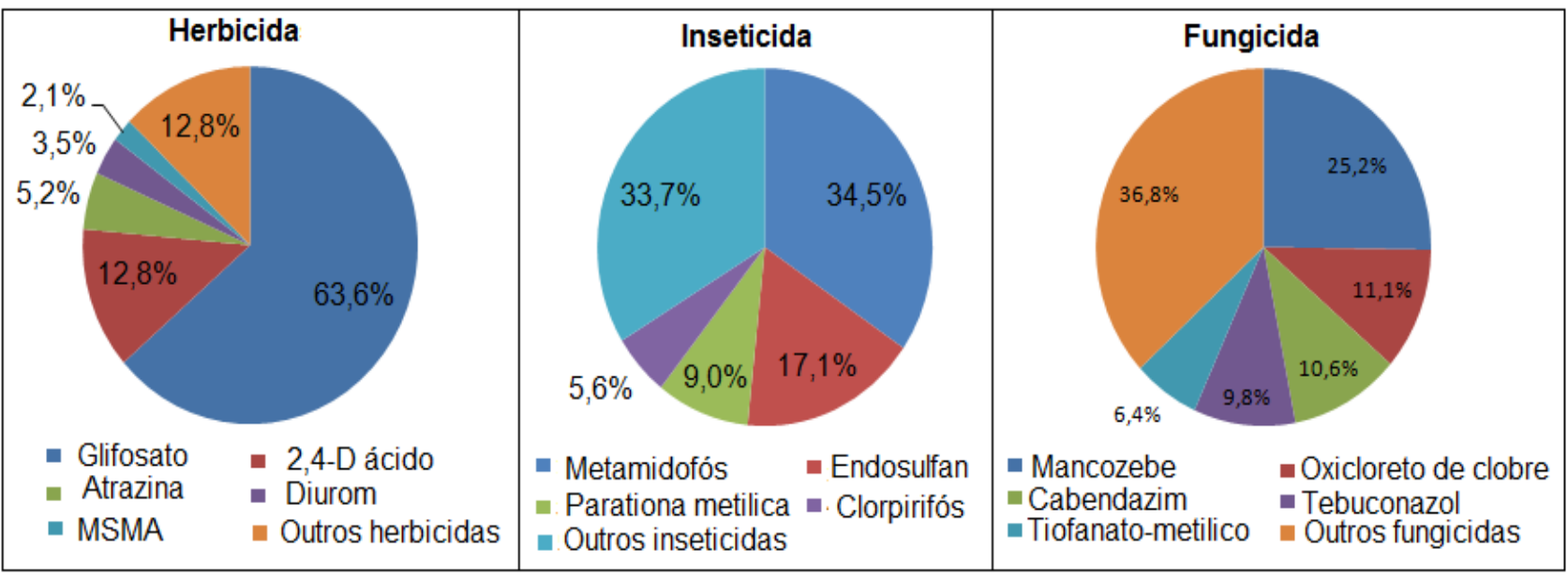

FIGURA 1: Distribuição dos ingredientes ativos de agrotóxicos, por classe de uso - Brasil - 2005 Fonte: IBAMA, 2006 apud IBGE, 2010

De acordo com o levantamento realizado pela CETESB (2010), utilizando a relação troca entre produtos agrícolas e defensivos, do Instituo de Economia Agrícola (IEA), os ingredientes ativos utilizados na cana-de-açúcar no Estado de São Paulo no 1ำ semestre de 2009 foram: 2,4-D, ametrina, clomazona, hexazinona + diuron, MSMA (herbicidas); fipronil (iseticida); endossulfam (acaricida e insetisida) e etefom (regulador de crescimento).

Um levantamento dos agrotóxicos utilizados na cultura de cana-de-açúcar na região da sub-bacia do Rio Corumbataí (Integrante da bacia do Rio Piracicaba), entre janeiro de 2000 a dezembro de 2003, destaca os herbicidas como a classe mais empregada, entre eles estão: o glifosato, atrazina, ametrina, 2,4-D, metribuzim, diuron e acetocloro representando $85 \%$ do volume total de produtos consumidos nesse período. $O$ restante corresponde a: halossulfurom, hexazinona, imazapique, MSMA, paraquate, picloram, simazina, tebutiurom, trifluralina entre outros utilizados nesse período. (ARMAS et. al. 2005). Outro estudo realizado entre 2004 e 2005 na mesma sub-bacia detectaram em amostras de água os herbicidas hexazinona, glifosato, clomazona e do grupo das triazinas (ametrina, atrazina e simazina), sendo a cultura de maior expressão a de canade-açúcar. Os níveis de detecção mais elevados foram das triazinas: ametrina 0,7-2,9 $\mu \mathrm{g} \cdot \mathrm{L}^{-1}$, atrazina $0,6-2,7 \mu \mathrm{g} \cdot \mathrm{L}^{-1}$ e simazina $0,3-0,6 \mu \mathrm{g} \cdot \mathrm{L}^{-1}$. (ARMAS et. al 2007).

Com base em receituários agrônomos emitidos, Luiz, Nevez e Dynia (2004, p. 29) constaram que o principal potencial de contaminação está relacionado ao uso do 
herbicida à base de tebutiuron, utilizado na cultura de cana-de-açúcar nos Municípios de Cosmópolis e Santa Bárbara d' Oeste. Os produtos a base de metamidofós, acetato e ametrina utilizados em batata, tomate e milho nos municípios de Monte Mor e Campinas, vem em um segundo nível de risco, no mesmo nível dos produtos à base de metamidofós e acefato (tomate) em Sumaré; produtos a base de diuron, clomazona e ametrina (canade-açúcar) em Cosmópolis e Santa Bárbara d' Oeste; e os produtos a base de diuron e ametrina (citros) em Artur Nogueira e Engenheiro Coelho.

Em 2009, os dez ingredientes ativos mais comercializados no Brasil foram glifosato e seus sais, cipermetrina, óleo mineral, óleo vegetal, enxofre, 2,4-D, atrazina metamidofos, acefato e carbendazim, equivalente a $76,45 \%$ do total de ingredientes comercializados. A Tabela 1 mostra esses compostos com relação à destinação às culturas. Dentro das principais culturas da região Oeste Paulista, a cana-de-açúcar, a soja e o milho, destacam-se a utilização de glifosato, cipermetrina, enxofre, 2,4-D, atrazina, metamidofós. (IBAMA, 2010; IBGE, 2010; SEADE, 2013).

TABELA 1: Relação das principais culturas $x$ dez ingredientes ativos mais utilizados

\begin{tabular}{|c|c|c|c|c|c}
\hline $\begin{array}{c}\text { INGREDIENTE } \\
\text { ATIVO (IA) }\end{array}$ & \multicolumn{5}{|c}{ CULTURA } \\
\cline { 2 - 6 } & Cana-de-açúcar & Soja & Milho & $\begin{array}{c}\text { Laranja } \\
\text { (citros) }\end{array}$ & Arroz \\
\hline $\begin{array}{c}\text { Glifosato e seus } \\
\text { sais }\end{array}$ & $\mathrm{S}$ & $\mathrm{S}$ & $\mathrm{S}$ & $\mathrm{S}$ & $\mathrm{S}$ \\
\hline $\begin{array}{c}\text { Cipermetrina } \\
\text { Óleo mineral }\end{array}$ & $\mathrm{N}$ & $\mathrm{S}$ & $\mathrm{S}$ & $\mathrm{N}$ & $\mathrm{S}$ \\
\hline Óleo vegetal & $\mathrm{N}$ & $\mathrm{N}$ & $\mathrm{N}$ & $\mathrm{S}$ & $\mathrm{N}$ \\
\hline Enxofre & $\mathrm{N}$ & $\mathrm{N}$ & $\mathrm{N}$ & $\mathrm{S}$ & $\mathrm{N}$ \\
\hline 2,4-D & $\mathrm{S}$ & $\mathrm{S}$ & $\mathrm{S}$ & $\mathrm{N}$ & $\mathrm{N}$ \\
\hline Atrazina & $\mathrm{S}$ & $\mathrm{N}$ & $\mathrm{S}$ & $\mathrm{N}$ & $\mathrm{S}$ \\
\hline Metamidofós & $\mathrm{N}$ & $\mathrm{S}$ & $\mathrm{N}$ & $\mathrm{N}$ & $\mathrm{N}$ \\
\hline Acefato & $\mathrm{N}$ & $\mathrm{S}$ & $\mathrm{N}$ & $\mathrm{S}$ & $\mathrm{N}$ \\
\hline Carbendazim & $\mathrm{N}$ & $\mathrm{S}$ & $\mathrm{N}$ & $\mathrm{S}$ & $\mathrm{N}$ \\
\hline
\end{tabular}

S: sim; N: não

Fonte: MAPA, 2010 apud IBAMA, 2010. 
De acordo com o levantamento e estudo realizados, que consideram a extensa área canavieira paulista e a previsão de aumento na produção e instalação de novas usinas para atender a demanda interna e externa de álcool nos próximos anos, considera a cana-de-açúcar como a cultura representativa do Estado de São Paulo e do Oeste Paulista. (CESTEB, 2010; DIAS, GUIMARÃES, GUIMARÃES, 2013). Logo, de acordo com os ingredientes ativos utilizados nesta cultura, pode-se destacar uma significativa utilização de glifosato, atrazina e 2,4-D na região do Oeste Paulista, onde esta cultura se destaca segundo alguns autores. (SACH, MARTINS, 2007; TORQUATO, MARTINS, TAMOS, 2009; SEADE, 2013).

\section{3- AGROTÓXICOS: CLASSIFICAÇÃO, TOXICIDADE, IMPACTOS AMBIENTAIS (SAÚDE E MEIO AMBIENTE)}

Os agrotóxicos podem ser classificados de diversas maneiras, uma delas é de acordo com o modo de ação do ingrediente ativo no organismo alvo, podendo ser: acaricidas (ação em ácaros), bactericidas (ação em bactérias), fungicidas (ação em fungos), inseticidas (ação em insetos), herbicidas (ação em plantas daninhas), algicidas (algas), rodenticidas (roedores), entre outros. Outra maneira é a classificação toxicológica, que indica que o agrotóxico é de maior ou menor periculosidade. A Tabela 3 apresenta essa classificação.

TABELA 3- Classe toxicológica e cor da faixa no rótulo de produtos agrotóxicos

\begin{tabular}{c|c|c}
\hline Classe Toxicológica & Toxicidade do produto & Faixa indicativa de cor \\
\hline I & Extremamente tóxicos & Vermelha \\
\hline II & Altamente tóxicos & Amarela \\
\hline III & Mediamente Tóxicos & Azul \\
\hline IV & Pouco Tóxicos & Verde \\
\hline
\end{tabular}

Fonte: OPAS/OMS, 1997, p. 19

De acordo com a classificação toxicológica, quanto menor a classe maior será o perigo de dano ao meio ambiente, e com isso a cor da faixa apresentada nos 
rótulos varia de vermelha a verde, por exemplo: a Classe I apresenta maior perigo e é caracterizada pela faixa vermelha.

Outra forma de classificar é dada pela $\mathrm{DL}_{50}$, uma medida padrão de toxicidade aguda, onde são realizados testes com animais, e de acordo com o modo de exposição (via oral, dérmica ou respiratória) esses valores podem variar, estipulando a dose/concentração letal para $50 \%$ da população exposta, ou seja, a dose requerida para matar $50 \%$ da população de animais em teste. Então quanto menor o valor da $\mathrm{DL}_{50}$ maior será a toxicidade, apresentando maior risco ao ambiente e aos seres humanos (BAIRD, 2002).

Os agrotóxicos devem ser manipulados com cuidado, conhecer a dose correta de aplicação, utilizar equipamentos de proteção individual além de destinar as embalagens a locais corretos são fundamentais, pois uma utilização inadequada pode acarretar danos a saúde humana, animal e ambiental.

A dose de aplicação está diretamente relacionada com as contaminações de alimentos, que são consumidos pelas pessoas, podendo causar possíveis danos a saúde. Muitas vezes, os produtos são utilizados excessivamente, permanecendo como resíduos nos alimentos, alguns possuem seus limites máximos estabelecidos superados. Outras vezes, muitas substâncias proibidas (restrita naquela cultura, ou no Brasil) são utilizadas em várias culturas, como é evidenciado pelo Programa de Análise de Resíduos de Agrotóxicos em Alimentos (PARA) da Agência de Nacional de Vigilância Sanitária (ANVISA), que avalia os níveis de resíduos de agrotóxicos nos alimentos in natura que chegam à mesa do consumidor (ANVISA, 2011).

A problemática envolvida com a utilização de agrotóxicos engloba desde a aplicação até o destino final das embalagens, por isso é fundamental ter conhecimento das características dessas substâncias. Uma das principais fontes de contaminação do solo e água é a aplicação aérea dessas substâncias que segundo Rocha, Rosa e Cardoso (2009) o vento pode influenciar na dispersão do produto em spray, por apresentar vários tamanhos de partículas. Desta forma, o pesticida pode atingir áreas distintas do local de aplicação, como águas superficiais e solos que não eram o objetivo da aplicação. 
Outra forma de contaminação do meio ambiente e também de possível impacto à saúde humana é a disposição inadequada de embalagens vazias. De acordo com o Instituto Nacional de Processamento de Embalagens (INPEV), a maioria das embalagens é lavável, sendo fundamental a lavagem para a devolução e correta destinação final. Um exemplo é a tríplice lavagem, onde o agricultor faz um prévio tratamento das embalagens, enxaguando três vezes, de acordo com as recomendações. Segundo a Lei ํo 9.974 de 6 de Junho de 2000, que altera a Lei $n^{\circ} 7.802 / 89$, "dispõe sobre, [...] destino final dos resíduos e embalagens, o registro, a classificação, o controle, a inspeção e a fiscalização de agrotóxicos, [...]." (BRASIL, 2000) é de responsabilidade do usuário de agrotóxico efetuar a devolução das embalagens vazias (de acordo com as recomendações) aos estabelecimentos comerciais adquiridos, cabe as empresas produtoras e comercializadoras de agrotóxicos serem responsáveis por dar um destino final adequado a esses materiais.

De acordo com Baird (2002), os produtos orgânicos sintéticos presentes no meio ambiente são uma ameaça para a saúde animal e humana. Os estrogênios ambientais, também chamados de interferentes endócrinos, desreguladores endócrinos, afetam a saúde reprodutiva de organismos superiores. Estes compostos, segundo a Agência de Proteção Ambiental dos Estados Unidos (United States Environmental Protection Agency, USEPA) são produtos que tem o potencial de interferir na função do sistema endócrino, como na produção, liberação, transporte, metabolismo, ligação, ação ou eliminação de hormônios naturais do corpo que são responsáveis pela manutenção da homeostase e da regulação dos processos de crescimento, podem incluir produtos químicos sintéticos, como pesticidas, plastificantes, produtos farmacêuticos entre outros (GRAY et al., 2001). Logo, alguns agrotóxicos são considerados interferentes endócrinos, pois são substâncias que tem a capacidade alterar o funcionamento do sistema endócrino, mimetizando ou antagonizando os efeitos de hormônios esteroides, como estrógenos e andrógenos. Esta ação pode prejudicar o sistema reprodutivo (como exemplo, reduzindo a produção e qualidade de espermatozóides), causando câncer, entre outros efeitos que podem ser evidenciados mesmo em baixas concentrações (GHISELLI; JARDIM, 2007). 
Os herbicidas também têm apresentado vários efeitos sobre a saúde e o ecossistema. A maior classe é das triazinas, sendo a mais conhecida a atrazina. A atrazina não bioacumula-se de forma significativa, mas é bastante persistente, levando preocupação com as correlações entre altas concentrações em água de poço e o câncer e as malformações congênitas. Preocupante também é a relação de agricultores e pessoas expostas a altas concentrações deste produto apresentarem índices de câncer mais elevados e uma maior incidência de defeitos congênitos, já mostradas por exames preliminares de saúde (BAIRD, 2002; SPIRO; STIGLIANI, 2008).

Estudo realizado com a exposição de diuron em embriões e espermatozóides de ostra apresentou efeitos embriotóxicos e genotóxicos, como um aumento significativo de larvas anormais, em concentrações que podem ser encontradas no ambiente (efeitos observados acima de $0,05 \mu \mathrm{gL}^{-1}$ ). Segundo o autor "como diuron pode provocar defeitos de desenvolvimento, pode afetar significativamente as taxas de recrutamento de ostras, e também causar danos significativos no DNA do espermatozóide" (AKCHA; SPAGNOL; ROUXEL, 2012). Outros estudos mostraram que a exposição de ostras adultas a concentração de $0,3 \mu \mathrm{gL}^{-1}$ de diuron por 11 semanas, tiveram efeitos de aneuploidia que persistiu para a próxima geração, ou seja foi apresentado danos no material genético, tais como alterações no número de cromossomos (BOUILLY et. al. 2007). Esses resultados também foram observados após exposição de ostras à atrazina (BOUILLY et al. 2004).

Uma avaliação dos efeitos reprodutivos causados por um herbicida que tem em sua formulação o glifosato, em ratos Wistar, evidenciou a diminuição na produção diária de espermatozóide e um aumento no percentual de espermatozóides anormais (DALLEGRAVE, E. et al. 2007). Outro estudo mostrou que células humanas expostas a herbicidas a base de glifosato apresentaram danos no DNA, identificados pelo ensaio cometa, apresentaram danos ao DNA (GASNIER, C. et al. 2009). Resultados semelhantes foram obtidos por Cavalcante, Martinez e Sofia (2008) que realizaram o teste a avaliação dos efeitos genotóxicos em peixes.

Estudos realizados Feyzi-Dehkharagni et al (2012) investigaram os efeitos prejudiciais da atrazina no sistema reprodutivo masculino em ratos, os resultados 
mostraram que ocorreu anomalias no espermatozóide, quebra no DNA e imaturidade nuclear. Outros trabalhos também avaliaram a genotoxicidade da atrazina (RIBAS et al. 1995; TENNANT; PENG; KLIGERMAN, 2001; ZELJEZIC; GARAJ-VRHOVAC; PERKOVIC, 2006; SANTOS; MARTINEZ, 2012) identificando que este herbicida causa danos ao DNA em peixes, ratos e células humanas. Efeitos genotóxicos também foi evidenciada por estudos realizados com camundongos e ratos expostos a 2,4-D (VENKOV. et al. 2000; AMER; ALY, 2001; apud GUNNES, 2007).

De acordo o levantamento de Keith (1998); Ghiselli, Jardim (2007); THE LIST...(2005), muitos agrotóxicos são considerados interferentes endócrinos por várias organizações mundiais, dentre os compostos, encontram-se, a atrazina, 2,4-D, acetocloro, clomazona, metribuzim, simazina, trifluralina. Esses apresentam um uso significativo na principal cultura da região Oeste Paulista. Na Tabela 3, são listados os compostos, e as organizações que os considera como desreguladores endócrinos.

TABELA 3: Compostos considerados desreguladores endócrinos de acordo com algumas organizações.

\begin{tabular}{c|c|c|c|c|c|c}
\hline Agrotóxicos & UKEA & USEPA & JEA & WWF & Ger. EA & EU \\
\hline 2,4-D & & $\mathrm{x}$ & & $\mathrm{x}$ & & $\mathrm{x}$ \\
Acetocloro & & $\mathrm{x}$ & $\mathrm{x}$ & $\mathrm{x}$ & & \\
Atrazina & $\mathrm{x}$ & $\mathrm{x}$ & $\mathrm{x}$ & $\mathrm{x}$ & \\
Clomazona & & $\mathrm{x}$ & $\mathrm{x}$ & $\mathrm{x}$ & $\mathrm{x}$ & \\
Endossulfan * & $\mathrm{x}$ & & & $\mathrm{x}$ & & \\
Metribuzim & $\mathrm{x}$ & $\mathrm{x}$ & $\mathrm{x}$ & $\mathrm{x}$ & & \\
Simazina & $\mathrm{x}$ & $\mathrm{x}$ & & $\mathrm{x}$ & & \\
Trifluralina & $\mathrm{x}$ & & & \\
\hline
\end{tabular}

$\left(^{*}\right)$ Ingrediente ativo banido no Brasil.

USEKA: Agência Ambiental do Reino Unido; USEPA: Agência de Proteção Ambiental dos Estados Unidos; JEA: Agência Ambiental do Japão; WWF: Organização não Governamental; Ger. EA: Agência Federal do Meio Ambiente da Alemanha; EU: União Européia.

Fonte: KEITH (1998); GHISELLI, JARDIM (2007); THE LIST...(2005).

\section{4- CONCLUSÃO}

Percebe-se, portanto, que a utilização dos agrotóxicos provém de diversas modificações na agricultura, através do uso da tecnologia, originou um intenso aumento desses produtos sintéticos, que por sua vez, tem contribuído com diversos danos ao meio 
ambiente, como poluição das águas, danos a diversas espécies de animais, e também interferindo na saúde do ser humano.

Com isso é de grande importância estudos que identifiquem os impactos em doses de exposição ambiental, prevendo quais os possíveis danos que poderão ser causados por um composto, tanto em animais quanto em humanos. Dentro desse contexto estão análises in vivo e in vitro, que são essenciais para testes de toxicidade. Novas formas de estudo também estão sendo desenvolvidas para verificar a nível molecular, como os compostos químicos interagem com células humana, é o caso da Espectroscopia de espalhamento Raman, que terá um futuro promissor nesta questão.

\section{5- AGRADECIMENTOS}

A CAPES pela bolsa de mestrado concedida pelo Programa de Suporte à Pós-Graduação de Instituições de Ensino Particulares - PROSUP

\section{REFERÊNCIAS}

AKCHA, F.; SPAGNOL, C.; ROUXEL, J. Genotoxicity of diuron and glyphosate in oyster spermatozoa and embryos. Aquatic Toxicology, Amsterdan; v. 106-107, p. 104-113, 2012.

ANVISA- Agência Nacional de Vigilância Sanitária. Programa de Análise de Resíduos de Agrotóxicos em Alimentos (PARA) - Relatório de Atividades de 2010. Brasília, Dezembro, 2011. Disponível em: <

http://portal.anvisa.gov.br/wps/content/Anvisa+Portal/Anvisa/Inicio/Agrotoxicos+e+Toxicol ogia/Assuntos+de+Interesse/Programa+de+Analise+de+Residuos+de+Agrotoxicos+em +A limentos> Acesso em: 26 Ago. 2013.

ANVISA- Agência Nacional de Vigilância Sanitária. Seminário volta a discutir mercado de agrotóxicos em 2012, Brasília; 2012. Disponível em: <http://portal.anvisa.gov.br> Acesso em: 12 jun. 2013

ARMAS, E.D. et al. Uso de agrotóxicos em cana-de-açúcar na bacia do rio Corumbataí e o risco de poluição hídrica. Química Nova, São Paulo; v. 28, n. 6, p. 975-982, 2005.

ARMAS, E.D. et al. Diagnóstico espaço-temporal da ocorrência de herbicidas nas águas superficiais e sedimentos do rio Corumbataí e principais afluentes. Química Nova, São Paulo; v. 30, n. 5, p. 1119-1127, 2007. 
BAIRD, C. Química Ambiental. 2. ed. Bookman: Porto Alegre, 2002, cap. 6.

BOUILLY, K. et al. Impact of Diuron on Aneuploidy and Hemocyte Parameters in Pacific Oyster, Crassostrea gigas. Archives of environmental contamination and toxicology, New York; v. 52, n. 1, p. 58-63, 2007.

BOUILLY, K. et al. Persistence of atrazine impact on aneuploidy in Pacific oysters, Crassostrea gigas. Marine Biology, Berlin; v. 145, n. 4, p. 699-705, 2004.

BRASIL. Lei no 7.802 de 11 de julho de 1989 - Decreto n.․ 4.074, de 4 de janeiro de 2002. Dispõe sobre a pesquisa, a experimentação, a produção, a embalagem e rotulagem, o transporte, o armazenamento, a comercialização, a propaganda comercial, a utilização, a importação, a exportação, o destino final dos resíduos e embalagens, o registro, a classificação, o controle, a inspeção e a fiscalização de agrotóxicos, seus componentes e afins. Diário Oficial, Brasília; 08 de janeiro de 2002.

BRASIL. Lei $n^{\circ} 7.802$ de 6 de Junho de 200 - Altera a Lei no 7802 de 11 de julho de 1989, que dispõe sobre a pesquisa, a experimentação, a produção, a embalagem e rotulagem, 0 transporte, o armazenamento, a comercialização, a propaganda comercial, a utilização, a importação, a exploração, o destino final dos resíduos e embalagens, o registro, a classificação, o controle, a inspeção e a fiscalização de agrotóxicos, seus componentes e afins, e dá outras providências. Diário Oficial, Brasília; 07 de Junho de 2000.

CALVALCANTE, D. G. S. M.; MARTINEZ, C. B. R.; SOFIA, S. H. Genotoxic effects of Roundup $\AA$ on the fish Prochilodus lineatus. Mutation Research, Amsterdan; v. 655, n. 12, p. $41-46,2008$.

CARSON, R. Primavera Silenciosa. 1 ed. São Paulo: Gaia, 2010.

CETESB - Companhia de Tecnologia de Saneamento Ambiental. São Paulo. Proposta para derivação de critérios para contaminantes ambientais da agricultura. 2010. São Paulo: Cetesb, 2010. Disponível em:

<http://www.cetesb.sp.gov.br/agua/aguas-subterraneas/96-publicacoes-e-relatorios>. Acesso em: 19 mar. 2013

DALLEGRAVE, E. et al. Pre- and postnatal toxicity of the commercial glyphosate formulation in Wistar rats. Archives of Toxicology, Berlin; v. 81, n. 9, p. 665-673, 2007.

DIAS, L. S.; GUIMARÃES, E. M. A.; GUIMARÃES, R. B. Reflexões dos impactos ambientais na paisagem causadas pela cultura da cana-de-açúcar no Oeste Paulista, São Paulo, Brasil. $14^{\text {to }}$ ENCUENTRO DE GEÓGRAFOS DE AMÉRICA LATINA. Reencuentro de saberes territoriales latinoamericanos Lima. Perú. 08-12/abr. 2013. Disponível em:< http://www.egal2013.pe/11temas-geograficos-libres/> Acesso em: 30 set. 2013 
FERREIRA, C.R.R.P.; VEGRO, C.L.R.; CAMARGO, M.L.B. Defensivos agrícolas: rumo a uma retomada sustentável. Análises e Indicadores de Agronegócio, São Paulo; v. 3, n. 2, 2008

FEYZI-DEHKHARGANI, S. et al. Atrazine in sub-acute exposure results in sperm DNA disintegrity and nuclear immaturity in rats. Veterinary Research Forum, Paris; V. 3, n. 1, p. 19-26, 2012.

GASNIER, C. Glyphosate-based herbicides are toxic and endocrine disruptors in human cell lines. Toxicology, Amsterdan; v 262, n. 3, p. 184-191, aug. 2009.

GHISELLI, G.; JARDIM, W. F. Interferentes endócrinos no ambiente. Química Nova, São Paulo; v. 30, n. 3, p. 695-706, 2007.

GRAY, L.E. JR.; OSTBY, J.; FURR, J.; WOLF, C.J.; LAMBRIGTH, C.; PARKS, L., et al. Effects of environmental antiandrogens on reproductive development in experimental animals. Human Reproduction Update, Oxford v.7, p. 248-264, 2001.

GUNNESS, P. F. The effect of 2,4D on gene expression in cultured cells. 2007. $226 \mathrm{f}$. These (Masters of Science in the Toxicology Graduate Program. College of Graduate Studies and Research. University of Saskatchewan, Saskatoon.

IBAMA- Instituto Brasileiro do Meio Ambiente e dos Recursos Naturais Renováveis. REBELO, R. M, et al. Produtos agrotóxicos e afins comercializados em 2009 no Brasil: uma abordagem ambiental. Brasília, 2010.

IBGE-INSTITUTO BRASILEIRO DE GEOGRAFIA E ESTATÍSTICA. Indicadores de desenvolvimento sustentável. Rio de Janeiro, 2010. Disponível em: <http://www.ibge.gov.br>. Acesso em 3 abr. 2013.

INPEV (INSTITUTO NACIONAL DE PROCESSAMENTO DE EMBALAGENS VAZIAS). Responsabilidade do agricultor. São Paulo, (2013). Disponível em: < http://www.inpev.org.br/responsabilidades/triplice_lavagem/responsabilidade_agricultor/re sponsabilidade_agricultor.asp >. Acesso em: 19 abr. 2013

KEITH, L. H. Environmental endocrine disruptors. Pure and Applied Chem, Oxford, v. 70, n. 12, p. 2319-2326, 1998.

LUIZ, A.J.B.; NEVES, M.C.; DYNIA, J.F. Implicações potenciais na qualidade das águas subterrâneas das atividades agrícolas na Região Metropolitana de Campinas, SP. Embrapa Meio Ambiente, Boletim de Pesquisa e Desenvolvimento, Jaquariúna; v. 25, 33p, 2004.

MORRISON, H.I.; WILKINS, K.; SEMENCIW, R.; MAO, Y.; WIGLE, D. Herbicides and cancer. Journal of the national câncer institue, Carw; v. 84, p. 1866-1874, 1992.

ODUM, E. Ecologia. Ed. Guanabara, Rio de Janeiro, 1988 
OPAS (Organização Pan-americana da Saúde). Manual de vigilância da saúde de populações expostas a agrotóxicos. Ministério da Saúde, Secretaria de Vigilância Sanitária. Brasília: Organização Pan-americana da Saúde/OMS, 1997. Disponível em: <http://bvsms.saude.gov.br/bvs/publicacoes/livro2.pdf>. Acesso em 12 abr. 20013.

PERES, F.; ROZEMBERG, B.; LUCCA, S. R. Percepção de riscos no trabalho rural em uma região agrícola do estado do Rio de Janeiro, Brasil: agrotóxicos, saúde e meio ambiente. Caderno de Saúde Pública, Rio de Janeiro, v. 21, n. 6, p. 1836-1844, nov./dez., 2005

RIBAS, G. et al. Herbicide-induced DNA damage in human lymphocytes evaluated by the single-cell gel electrophoresis (SCGE) assay. Mutation Research, Amsterdan; v. 344, $n$. 1-2, p. 41-54, 1995.

ROCHA, J. C., ROSA, A. H, CARDOSO, A. A., Introdução à química ambiental. 2. ed. Porto Alegre: Bookman, 2009

SACHS, R.; MARTINS, V. A. Análise da cultura da cana-de-açúcar, por Escritório de Desenvolvimento Rural, Estado de São Paulo, 1995-2006. Informações Econômicas, São Paulo, v. 37, n. 9, p. 41-52, set. 2007.

SANTOS, T. G.; MARTINEZ, C. B. Atrazine promotes biochemical changes and DNA damage in a Neotropical fish species. Chemosphere, Oxford; v. 89, n. 9, p. 1118-1125, 2012.

SEADE. Anuário Estatístico do Estado de São Paulo: Fundação Sistema Estadual de Análise de Dados. São Paulo, 2013. Disponível em:

<http://www.seade.gov.br/produtos/anuario/>. Acesso em: 20 mar. 2013

SINDAG - Sindicato Nacional da Indústria de Produtos para Defesa Agrícola. Disponível. Conexão SINDAG. São Paulo, 2011. Disponível em:

<http://www.sindag.com.br/conexao/anteriores/conexao_n29.pdf>. Acesso em: 4 jun. 2013

SPIRO, T. G.; STIGLIANI, W. M. Química Ambiental. 2. ed. São Paulo: Pearson Prentice Hall, 2008-2009

TENNANT, A. H.; PENG, B.; KLIGERMAN, A. D. Genotoxicity studies of three triazine herbicides: in vivo studies using the alkaline single cell gel (SCG) assay. Mutation Research, Amsterdan; v. 493, n. 1-2, p. 1-10, jun. 2001.

THE LIST OF LISTS. A catalogue of lists of pesticides identifying those associated with particularly harmful health or environmental impacts. Briefing paper. Pesticide Action Network UK. London. 2005 
TORQUATO, S.A.; MARTINS, R.; RAMOS, S.F. Cana-de-açúcar no Estado de São Paulo: eficiência econômicas das regionais novas e tradicionais de produção. Informações Econômicas, São Paulo; v. 39, n. 5, 2009.

USEPA- United States Environmental Protection Agency. Endocrine Disruptor. 2013. Disponível em:< http://www.epa.gov/research/endocrinedisruption/faq.htm>. Acesso em: 20 abr. 2013

WEISENBURGER, D. Perspective in pathology: human health effects of agrichemical use. Human Pathology, Philadelphia; v. 24, p. 571-576, 1993.

ZELJEZIC, D.; GARAJ-VRHOVAC, V.; PERKOVIC, P. Evaluation of DNA damage induced by atrazine and atrazine-based herbicide in human lymphocytes in vitro using a comet and DNA diffusion assay. Toxicology In Vitro, New York; v. 20, n. 6, p. 923-935, 2006. 